\title{
Estimating the Level of the Brazilian Yield Curve Using the Time-Varying Coefficient Model GAS $(2,2)$ with Gamma Distribution
}

\author{
Daiane Rodrigues dos Santos ${ }^{1}$, Tiago Costa Ribeiro ${ }^{2} \&$ Marco Aurélio Sanfins ${ }^{3}$ \\ ${ }^{1}$ Cândido Mendes University, Rio de Janeiro - RJ, Brazil \\ ${ }^{2}$ FAPES, Rio de Janeiro - RJ, Brazil \\ ${ }^{3}$ Federal Fluminense University, RJ, Brazil \\ Correspondence: Daiane Rodrigues dos Santos, Cândido Mendes University, St. da Assembléia, 10 - Downtown, \\ Rio de Janeiro - RJ, Brazil. E-mail: daianesantoseco@gmail.com
}

Received: July 17, 2019

Accepted: August 3, 2019

Online Published: August 6, 2019

doi:10.5539/ijef.v11n9p1

URL: https://doi.org/10.5539/ijef.v11n9p1

\begin{abstract}
The level of the yield curve is strongly associated with a very important macroeconomic variable for developing economies: the inflation. Therefore, it becomes relevant for economic studies the development of a time series model that can accurately predict this variable. This article proposes the estimation and prediction of the yield curve level using the GAS (Generalized Autoregressive Score) class of time-varying coefficient models. The formulation of these models facilitates a general framework for time series modelling presenting a series of advantages, including the possibility of specifying any conditional distribution deemed appropriate for the yield curve level. In addition, the complete structure of the predictive distribution is transported to the mechanism that updates the time-varying parameters, via score function. When analyzing the evaluation criteria, the measures of adherence, and both Wilcoxon and Diebold \& Mariano tests, it was verified that the adjustment of the GAS model $(2,2)$ with gamma distribution to the series containing the Brazilian Yield Curve level of January 2006 and February 2017 presented a satisfactory result.
\end{abstract}

Keywords: GAS models, yield curves, long-term interest rate

\section{Introduction}

The interest rate is a relevant monetary policy instrument, which makes expectations of future interest rates an important predictive variable of the economy expectations. The combination of interest rates, with different maturities at a given time is called by the term structure of interest rates (Yield Curve). This structure contains the expectation of the interest rate for the future, from a given period. From this perspective, a line of study emerged, observing the relationship between these expectations and the macroeconomic information. The Yield Curve is used to observe the distribution of interest rates, on demand, of zero coupon bonds in different maturities for a given issuer. The Yield Curve is an important tool for investments in fixed income. Investors use it as a reference point for the prediction of interest rates and bond prices and, therefore, create strategies with the purpose of increasing the return of their investments.

According to Mascitelli (2008) the knowledge of the Yield Curve is of great importance for investment, economic policy, asset pricing, and for portfolio formation. This structure, over the past years, has also become an indicator of economic activity.

The yield curve can be decomposed and explained by three components: level, slope and curvature. The level is the component with the greatest explanatory potential about the Term Structure of Interest Rates. According to Luna (2006) most of the Yield Curve movements explanation, more accurately $89.5 \%$, are attributed to the factor level. This article aims at estimating and predicting this important long-term component, the level, using models with time-varying parameters, the GAS - Generalized Autoregressive Score Models.

In the literature review section, some works about the Yield Curve and its components, its relationship with macroeconomic variables, as well as a brief exposition of the initial works related to the chosen models. Section 2 presents the specifications and properties of the GAS models for the three distributions test of this article, the normal distribution, the Gamma distribution, and the Beta distribution. Section 3 describes the results, descriptive statistics of the data, the applied normality tests (Lilliefors, Shapiro-Wilk and Anderson-Darling), the 
parameters estimated for all three distributions tested, as well as the tests and diagnoses applied to the waste, the criteria for model assessment and the chosen efficiency tests named Wilcoxon and Diebold \& Mariano. Section 4 presents the main conclusions of this paper. Finally, section 5 describes the possible future developments of this research.

\section{Literature Review}

The yield curve can be modeled using the metrics of main components of Siegel (1987) and Diebold and Li (2006) this methodology is considered, in the literature, as a benchmark in The Yield Curve estimation.

"Nelson Siegel's model establishes a functional form of four parameters that seeks to approximate the forward rate curve by a sum of exponential functions. It is a parametrically parsimonious model able to generate term structures with very similar formats to those observed in the financial market" (Franklin et al., p. 8, 2012).

The Nelson-Siegel technique was used by Diebold and Li (2006) to model the Yield Curve. They showed that time-varying parameters can be interpreted as factors corresponding to the level, slope and curvature and that can be estimated with high efficiency. In This model the Yield Curve can be decomposed and explained by three components, namely: $\beta_{1}, \beta_{2}$ and $\beta_{3}$, that can identify the movements in the level, in the slope and in the curvature of the interest curve, respectively. The first component $\beta_{1}$ is associated with essentially parallel movements that occur in instruments with long- and short-term maturities, but with less intensity in the short-term. Litterman and Scheinkman (1991) realized that the second component reflects the slope of The Yield Curve. This interpretation was verified when the rotation that occurred in relation to an average curve was observed. The third component was called by the authors curvature. As described by Litterman and Scheinkman (1991) it is mainly associated with volatility.

\subsection{Interest Rate and Macroeconomic Variables}

According to Shousha (2008) in Brazil as in most industrialized countries, the Central Bank uses as a monetary policy instrument the short-term interest rate. However, it is the longest rates that matter to determine the aggregated demand. This is because the agents' credit cost depends on rates with different terms. As Shousha (2008) defined, long-term interest rates are determined by the future expectation of short-term rates adjusted by the risk of withholding such securities. These long-term rates have a risk premium component associated with the duration of the contracts, also known as term premium.

Based on Siegel (1987) whatever the objectives of economic policies may be, The Yield Curve should be considered by its effects on the level of activity and on inflation, through consumption. The Yield Curve is also important for investors in the financial market because it serves as a reference for calculating the expected returns from more elaborated financial operations, for instance operations that involve credit risk, with coupon payment, or post-fixed rates.

Silveira (2005) and Matsumara and Moreira (2005) apud Shousha (2008) are the first authors to explicitly employ macroeconomic variables in a curve model to try to explain the dynamics of The Yield Curve. A potential cause for this incipience is the absence of long-term applications in Brazil because of the long inflationary experience and economic instability.

In his article Obara (2014) detected an association between macroeconomic variables and The Yield Curve. According to the author, this result may indicate a dynamic in which the agents observe the macroeconomic variables and, because of this information, he transfer their monetary policy expectations throughout The Yield Curve.

Numerous studies have shown that the level component (long-term interest) is related to a very important macroeconomic variable, mainly for underdeveloped countries, that is, inflation (Ejsing, Garcia, \& Werner, 2007; Shousha, 2008; Vicente \& Graminho, 2014; and Bernz, 2014). Therefore, estimating this variable correctly can help predict inflation.

In macroeconomic terms, the mapping of the Yield Curve components allows a greater visibility of the monetary policy effects on the real side of the economy. In this sense, this article aims to model one of the three components of the Yield Curve, the level, referred to in the literature as a long-term component. According Diebold and $\mathrm{Li}$ (2006) the level component is mainly associated with movements in the interest rates with long-term maturity. In his article Chirinos-Leañez and Pagliacci (2015) also conclude that the level component is associated with expectations of income from long-term securities. 


\section{Gas - Models with Time-Varying Parameters}

The estimation of Brazilian Yield Curve level - long-term rate, $\beta_{1}$, - was carried out by using a class of time-varying coefficient models, called GAS (Generalized Autoregressive Score). These models, also known as Dynamic Conditional Score (DCS), developed by Creal et al. (2008) provide a general framework for modelling time series and panel data. From this framework it is possible to specify and estimate any conditional distribution which is considered appropriate to the level of the Brazilian interest rate.

In GAS models, likelihood is available in closed form, which is not the case for state space models with non-Gaussian distributions. In addition, the complete structure of the predictive distribution is carried to the mechanism of updating the time-varying parameters, via score function (Equation 5). These are some of the advantages of the models proposed in this article, compared to the models already consolidated in the literature.

Some well-known models used in the literature can be seen as particular cases of GAS models. Examples include conditionally heteroscedastic autoregressive models (GARCH) by Engle and Bollerslev (1986), the autoregressive models of intensity and conditional duration, by Engle and Russell (1998) and Engle's (2002) multiplicative error (MEM) models.

\subsection{Gas Models - Specifications and Properties}

Consider $y_{t}$ a stochastic process with continuous state space, $f_{t}$ and $\Psi$ vectors with time varying and static parameters, respectively. In addition, the information sets $Y^{t}=\left(y_{1}, y_{2}, \ldots, y_{t}\right)$ and $\$ F^{t}=\left(f_{0}, f_{1}, \ldots, f_{t}\right)$ are also defined. Thus, we characterize all information available until time $t-1$ as:

$$
F_{T-1}=\left\{Y^{T-1}, F^{T-1}\right\}, \text { for } t=1,2 \ldots T
$$

The conditional density is represented by:

$$
y_{t} \sim p\left(y_{t} \mid f_{t}, F_{t-1} ; \Psi\right)
$$

The mechanism for updating $f_{t}$, is similar to the one adopted in $\operatorname{ARMA}(\mathrm{p}, \mathrm{q})$ model as it follows.

$$
f_{t+1}=\omega+\sum_{i=1}^{p} A_{i} s_{t-i+1}+\sum_{j=1}^{q} B_{j} f_{t-j+1}
$$

where $\omega$ is a vector of constants, the matrices $A_{i}$ and $B_{i}$ have adequate dimensions, determined by the dimensions of $s_{t}$ and $f_{t} . s_{t}$ is a function of the past data, $s_{t}=f\left(y_{i}, f_{i} ; \Psi\right)$, to be detailed.

The estimate of the factors in time, $f_{t}$, given the past observations, $Y_{T-1}=\left(y_{1}, \ldots, y_{t-1}\right)$, for a value of $\Psi$, is similar to the filtering process of the models in state space ([13]). When the observation $y_{t}$ becomes available, $s_{t}$ is computed as defined in Equation (4). In practice, the filtering process starts at time $t=1$ with $f_{1}$ being a fixed value or, as in this article, being part of the vector of unknown parameters, $\Psi$.

As in Creal et al. (2008). the weighted score vector, $s_{t}$, present in Equation (3) is defined as being:

$$
s_{t}=S_{t}\left(F_{t-1}\right) \nabla_{t}=S_{t} \nabla_{t}
$$

The score vector, $\nabla_{t}$ contained in Equation (4), is given by:

$$
\nabla_{t}=\frac{\partial \log P\left(y_{t} \mid f_{t}, F_{t-1} ; \Psi\right)}{\partial f_{t}}
$$

$S_{t}$ is a weighting matrix obtained from the Fisher information matrix, being given by:

$$
S_{t}=I_{t \mid t-1}^{-d} \quad d=0, \frac{1}{2}, 1
$$

Where

$$
I_{t \mid t-1}=E_{t-1}\left(\nabla_{t}, \nabla^{\prime}{ }_{t}\right)=E_{t-1}\left[\frac{\partial^{2} \log P\left(y_{t} \mid f_{t, F t-1} ;\right)}{\partial f_{t} \partial f_{t}^{\prime}}\right]
$$

Being $E_{t-1}(\cdot)=E_{t-1}\left(\cdot \mid f_{t}, F_{t-1} ; \Psi\right) \$$. The weighting mechanism of the score vector present in Equation (4) is a relevant feature of GAS models. Choosing $d=0$ the identity matrix $\left(S_{t}=I\right)$ can be obtained, with which the update mechanism starts to use only the gradient for updating the time-varying parameters. If $d=1 / 2$, then one can show that $E_{t-1}\left(s_{t}\right)=0$ and $V_{t-1}\left(s_{t}\right)=1$, that is, $s_{t}$ is a martingale difference with unit variance process.

\subsection{GAS Models with Gamma Density}

As already describe in this article, the following distributions were tested: normal, gamma and beta. As the gamma distribution proved to be the most adequate for the data set, this section deals with the GAS models with this distribution. The time-varying parameter in this application is the scale parameter, $\beta_{t}$.

The density for each $y_{t}$ (level of the yield curve) will be given by Equation (8).

$$
\mathrm{p}\left(y_{t} \mid \alpha, \beta_{t}, F_{t-1}\right)=\frac{\beta_{t}^{\alpha}}{\Gamma(\alpha)} y_{t}^{\alpha-1} e^{\beta_{t} y_{t}}, \quad y_{t}>0
$$


The expected value and variance of a gamma distribution are given below:

$$
\begin{gathered}
E\left[y_{t} \mid \alpha, \beta_{t}, F_{t-1}\right]=\frac{\alpha}{\beta_{t}} \\
V\left[y_{t} \mid \alpha, \beta_{t}, F_{t-1}\right]=\Psi\left(\alpha_{t}\right)-\log \left(\beta_{t}\right)
\end{gathered}
$$

As seen, for the development of the GAS model (p,q) it will be necessary to calculate the score vector, $\nabla_{t}$ and Fisher's information matrix, $I_{t \mid t-1}$ following that:

$$
\begin{gathered}
\nabla_{t}=\frac{\partial \log P\left(y_{t} \mid \alpha, \beta_{t}, F_{t-1}\right)}{\partial f_{t}}=\frac{\alpha}{\beta_{t}}-y_{t} \\
I_{t \mid t-1}=E_{t-1}\left(\nabla_{t}, \nabla^{\prime}{ }_{t}\right)=\frac{-\alpha}{\beta_{t}^{2}}
\end{gathered}
$$

The GAS model $(2,2)$ with gamma distribution to model the dependency structure between the levels of the Brazilian interest rate is presented below.

$$
f_{t+1}=\omega_{1}+\omega_{2}+A_{1} s_{t}+A_{2} s_{t-1}+B_{1} f_{t}+B_{2} f_{t-1}
$$

In which, for this application, $s_{t}$ is equal to:

$$
S_{t}=I_{t \mid t-1}^{-d}=\frac{1}{\sqrt{\frac{-\alpha}{\beta_{t}^{2}}}} \frac{\alpha}{\beta_{t}}-y_{t}
$$

A crucial step in the data statistical modeling is the investigation of the probability of the model used, to be a reasonable approximation to the true data, generating probability mechanism. In this article, the diagnostics for the models evaluation are based on tests performed on Pearson residual. The Pearson residual is defined as:

\section{Results}

$$
r_{t}=\frac{y_{t}-E\left[y_{t} \mid \alpha, \beta_{t}, F_{t-1}\right]}{\sqrt{V\left[y_{t} \mid \alpha, \beta_{t}, F_{t-1}\right]}}
$$

This article used monthly closing spreads of the Brazilian Yield Curve, based on federal government bond rates (NTN-B) (Note 1), provided by the Brazilian Association of Financial and Capital Market Entities - ANBIMA. Altogether, 134 observations were used, referring to monthly data between January 2006 and February 2017.

According to a methodological manual available on ANBIMA's (Note 2), website, the development of the Yield Curve is based on Svensson's 4-factor model, using the rates of NTN-Bs. To simplify the interpretation of the results, the Yield Curve estimated by ANBIMA under the aegis of Svensson's 4-factor model (op.cit.) was used to obtain the level of interest rate (long-term rate). The time series formed by Yield Curve levels from January 2006 to February 2017 is shown in Figure. 1.

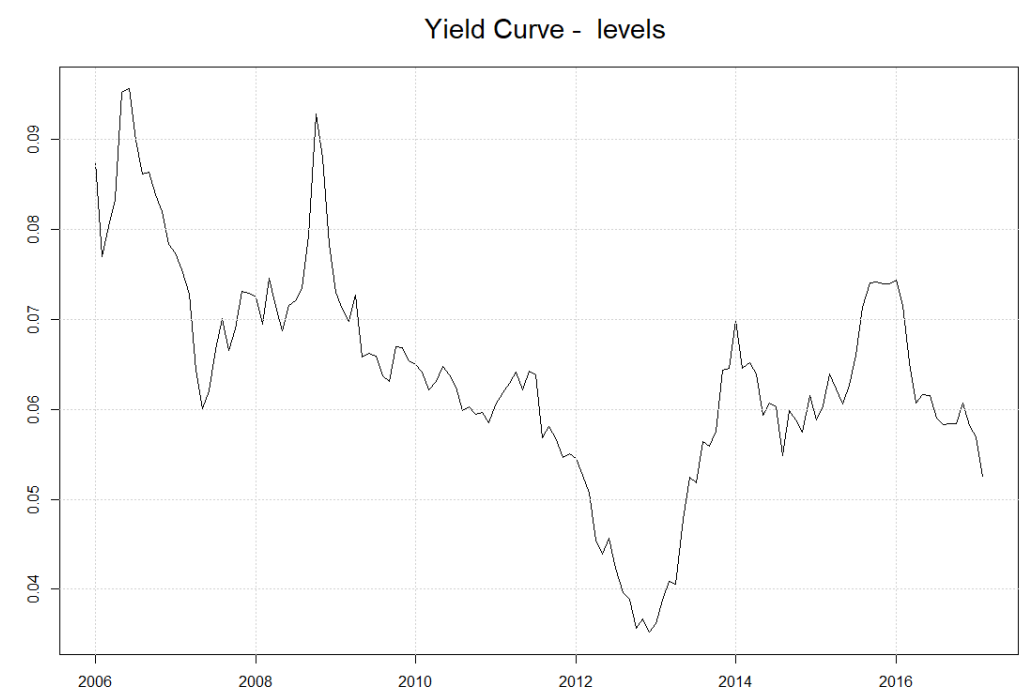

Figure 1. Level of the yield curve from January 2006 to February 2017

The year of 2006 was chosen as the beginning of the series, since it was the year that the Notes of the National Treasury - B Series (NTN-B) consolidated itself as the main government bond, in terms of traded volume, indexed at price level. As mentioned by the Ministry of Planning in 2006 via Budget Law, the government started in the year of that publication the program of exchanging shorter NTN-B vertices for longer vertices, with 
the objective of lengthening the federal public debt profile and stimulating the liquidity of titles (Note 3).

As it can be seen in Figure 1, the highest long-term rate was in June 2006, 0.0956 (9.56\%) and the lowest rate was in December 2012, 0.351 (3.51\%). The period considered in this article was from January 2006 to February 2017, as previously specified. The data series was divided into two samples, one for the estimation (of January 2006 to August 2012) and another for predicting (from September 2012 to February of 2017). The Tab.1 presents the descriptive statistics for the complete serie (134 observations) and for samples from the same In-sample ( 80 observations) and Out-of-sample (54 comments). The Table 1 presents some normality tests applied to the samples.

Table 1. Normality tests for the Level of the rate

\begin{tabular}{ccccccc}
\hline & \multicolumn{3}{c}{ Normality tests } & & & OS \\
\hline Level of the rate & \multicolumn{2}{c}{ FS } & & IS & & \multicolumn{1}{c}{ P-value } \\
\cline { 2 - 7 } & stat. & P-value & stat. & P-value & stat. & 0.000 \\
Lilliefors & 0.092 & 0.008 & 0.087 & 0.144 & 0.178 & 0.000 \\
S-W & 0.971 & 0.006 & 0.980 & 0.242 & 0.896 & 0.000 \\
A-D & 1.471 & 0.001 & 0.628 & 0.098 & 2.087 & 0.000 \\
\hline
\end{tabular}

Note. FS= Full Serie; IS= In-Sample; OS=Out-of-Sample, S-W=Shapiro-Wilk, A-D=Anderson-Darling.

The performed normality tests were: Lilliefors, Shapiro-Wilk and Anderson-Darling. All tests have as null hypothesis $\left(H_{0}\right)$ that the series come from a normal population. As it can be seen in Tab. 1, for the complete series and the Out-of-sample Series, the normality hypothesis is rejected, to the usual significance levels (5\% and $10 \%)$. For the In-sample series, the normality hypothesis is accepted.

The Table 2 illustrates the analyzed models, presenting the associated distribution, the parameters considered in each of them and then which parameter is variant in time.

Table 2. Models analyzed

\begin{tabular}{cccc}
\hline Model & Distribution & Parameter & TV parameter $\left(f_{t}\right)$ \\
\hline GAS $(2,2)$ normal & normal & mean and variance & variance \\
GAS $(2,2)$ gamma & gamma & shape and scale & scale \\
GAS $(2,2)$ beta & beta & shape and scale & shape \\
\hline
\end{tabular}

Note. $\mathrm{TV}$ parameter $=$ Time variant parameter.

It should be noted that the GAS models (p,q) were tested (Adjusted) with all two parameters varying in time, as well as each individually. The Tab. 2 presents the model with the respective time-varying parameter that best fit to the data. The Table 3 presents the estimates of all statistical parameters, to each estimated parameter it is presented the standard deviation of the estimation, the t-statistic, and the p-value associated, which has the purpose of verifying if the estimated parameter is significant. Considering a level of 5\% confidence, $p$-values lower than this level of significance lead us to reject the null hypothesis that the parameter is equal to zero.

Table 3. Estimates of statistical parameters

\begin{tabular}{ccccc}
\hline Parameters & Estimates parameters & SD & statistic of test & P-value \\
\hline$\omega_{1}$ & GAS with normal distribution & & 0.0000 \\
$\omega_{2}$ & 0.0649 & 0.0010 & 67.7385 & 0.0147 \\
$A_{1}$ & -1.5686 & 0.7202 & -2.1781 & 0.0001 \\
$A_{2}$ & 1.3753 & 0.3748 & 3.6697 & 0.0000 \\
\hline$\omega_{1}$ & 0.8209 & 0.0812 & 10.1142 & 0.0000 \\
$\omega_{2}$ & GAS with gamma distribution & 0.0000 \\
$A_{1}$ & 0.0029 & 0.0000 & 65.5356 & 0.0000 \\
$A_{2}$ & 0.0042 & 0.0001 & 81.1081 & 0.0000 \\
$B_{1}$ & 0.0000 & 0.0000 & 7763.3921 & 0.0000 \\
$B_{2}$ & 0.0333 & 0.0000 & 1993866.7640 & 0.0000 \\
\hline
\end{tabular}




\begin{tabular}{ccccc}
\hline \multicolumn{5}{c}{ GAS with beta distribution } \\
\hline$\omega_{1}$ & 0,0016 & 0.0000 & 72.0479 & 0.0000 \\
$\omega_{2}$ & 0.0038 & 0.0000 & 100.2267 & 0.0000 \\
$A_{1}$ & 0.0000 & 0.0000 & 962.4840 & 0.0000 \\
$A_{2}$ & 0.0039 & 0.0000 & 1336.1932 & 0.0000 \\
$B_{1}$ & 0.9997 & 0.0000 & 474386.7627 & 0.0000 \\
$B_{2}$ & 0.9995 & 0.0000 & 383404.0605 & 0,0000 \\
\hline
\end{tabular}

The statical parameters presented in Table 3 are related to the updating of the time-varying vectors of the GAS models (Equation 3). The statical parameters were estimated via maximum likelihood. To select the dependency dimension of the GAS models, (p,q), it was initially estimated the static version of the model (that is, with $A=0$ and $B=0$ ) and from the evaluation criteria, the dimensions were deepened, and then the most suitable $(\mathrm{p}, \mathrm{q})$ for each distribution (normal, gamma and beta) were selected.

The Table 4 presents the AIC and BIC evaluation criteria. These criteria shall be used to evaluate which model has the best fit. It should be noted that the selected evaluation criteria increase according to the sum of the quadratic errors, therefore, smaller values of these measures are preferable.

Table 4. Evaluation criteria

\begin{tabular}{ccc}
\hline Models/Evaluation criteria & AIC & BIC \\
\hline GAS $(2,2)$ with normal dist. & -540.65 & -531.13 \\
GAS $(2,2)$ with gamma dist. & -669.23 & -654.94 \\
GAS $(2,2)$ with normal dist. & -668.71 & -654.41 \\
\hline
\end{tabular}

The Table. 5 presents the tests of Heteroscedasticity, Box-Ljung and Jarque-Bera in Pearson residuals.

Table 5. Tests and diagnostics applied to the residual, model GAS $(2,2)$ with gamma distribution

\begin{tabular}{cc}
\hline Test & PS \\
\hline Heteroscedasticity \& (Chi-Square) & 0.523 \\
Autocorrelation (serie) \& Ljung Box & 0.073 \\
Autocorrelation square) \& Ljung Box & 0.220 \\
Normality \& Jarque-Bera & 0.287 \\
\hline
\end{tabular}

Note. PS- Pearson's Residue.

In the Homoscedasticity (Chi-Square) test the p-value did not suggest rejection of $H_{0}$, which means that, there is no evidence of heteroscedasticity. In the Box-Ljung test, there is no evidence to reject the null hypothesis, which means that, the residuals are uncorrelated. In the Jarque-Bera normality test, the null hypothesis, the hypothesis of normality of Pearson residuals, is not rejected.

To assist in the residual analysis of the GAS model $(2,2)$ with gamma distribution, in Annex there is a graph of the residuals and the associated autocorrelation functions.

We use State Space Models - SSM (Note 4) to compare the results obtained under de GAS models. Accuracy measures can be found on Tables 6 and 7 (Note 5).

Table 6. Measures of accuracy within the sample

\begin{tabular}{|c|c|c|c|}
\hline Model/ Measures & MAPE (\%) & $\mathrm{EQM}\left(+10^{4}\right)$ & Pseudo $R^{2}(\%)$ \\
\hline GAS $(2,2)$ normal & 13.46 & 1.44 & 18.40 \\
\hline GAS $(2,2)$ gamma & 6.40 & 1.91 & 40.35 \\
\hline GAS $(2,2)$ beta & 6.56 & 1.96 & 40.31 \\
\hline SSM & 7.54 & 1.53 & 45.65 \\
\hline
\end{tabular}


Table 7. Measures of accuracy out-sample

\begin{tabular}{cccc}
\hline Model/ Measures & MAPE $(\%)$ & EQM $\left(+10^{4}\right)$ & Pseudo $R^{2}(\%)$ \\
\hline GAS $(2,2)$ normal & 31.03 & 4.57 & 0.19 \\
GAS $(2,2)$ gamma & 14.49 & 1.36 & 22.19 \\
GAS $(2,2)$ beta & 19.28 & 1.55 & 70.7 \\
SSM & 4.45 & 0.10 & 91.20 \\
Random Walk & 4.61 & 0.11 & 90.26 \\
\hline
\end{tabular}

As it can be seen in Table 6 (measurements of adherence calculated for the estimation series), the MAPE and the Pseudo $R^{2}$ evaluation criteria, shows a better accuracy on the GAS model $(2,2)$ with gamma distribution. The EQM evaluation criteria points to a better accuracy on the SSM. According to Table 3 (measurements of adherence calculated for the predicting series), all the evaluation criteria points to a better accuracy on the GAS model $(2,2)$ with gamma distribution.

In Tab. 8 can be found the p-values of the Wilcoxon and Diebold \& Mariano tests. The tests were applied to the estimation series (from January 2006 to 2012), using GAS models (2,2) with the normal, gamma and beta distributions. In addition, the State Space Models was also used.

The Wilcoxon test is an extension of the signal test. The test development is based on random samples from continuous populations. The data is transformed into counts of a dichotomous variable, that correspond to the observations below or above the median. In the present study, $d$ is the difference between errors made in the adjustment of the model $(i)$ and the errors made by the adjustment of the model $(j)$. The hypotheses in this case are: $H_{0}$, the adjustments provided by the two models $(i, j)$ are equivalent; and in $H_{1}$, the adjustment provided by the model $(i)$ is better than the adjustment provided by the model $(j)$. Further details of the test are in Ferreira (2013).

To assist in the decision-making regarding the most efficient model, the Diebold \& Mariano test was employed. The test has the purpose of comparing the precision of predictions obtained through two different models. The loss function used was MAPE. The null hypothesis, $H_{0}$, is that the model $(i)$ and the model $(j)$ generate predictions of the same precision, and the alternative hypothesis, $H_{1}$ is the hypothesis that the model $(i)$ is more accurate than the model $(j)$. Further details of the test are found in Diebold and Mariano (1995).

Table 8. Adjustment and efficiency tests - Wilcoxon test and Diebold and Mariano test

\begin{tabular}{cccc}
\hline Model (i) & Model (j) & Statistics Z (Wilcox) & P-value (DW) \\
\hline GAS $(2,2)$ normal dist. & SSM & 5.295 & 0.110 \\
GAS $(2,2)$ gamma dist. & SSM & 5.002 & 0.086 \\
GAS $(2,2)$ beta dist. & SSM & 1.721 & 0.086 \\
GAS $(2,2)$ normal dist. & GAS $(2,2)$ beta dist. & 4.926 & 0.077 \\
GAS $(2,2)$ gamma dist. & GAS (2,2) normal dist. & 1.636 & 0.005 \\
GAS $(2,2)$ with beta dist. & GAS (2,2) with gamma dist. & 5.568 & 0.005 \\
\hline
\end{tabular}

As it can be seen in the Tabble 8 in Wilcoxon's non-parametric test for two paired samples, we accept the alternative hypothesis that the adjustment provided by the GAS model (2.2) is better than the adjustment provided by the State Space Models. In the Diebold \& Mariano test it is accepted that the GAS model $(2,2)$ with gamma and beta distribution is more accurate than the State Space Models.

According to the Table 8, in Wilcoxon's test, the alternative hypothesis that the adjustment provided by the GAS model $(2,2)$ with gamma distribution is better than the adjustment provided by model GAS $(2,2)$ with beta distribution is accepted. In the Diebold \& Mariano test, the hypothesis that the GAS model $(2,2)$ with gamma distribution and the GAS model $(2,2)$ with beta distribution generate predictions of the same accuracy is accepted. It should be noted that the loss function used was MAPE, and as it can be observed in Table 6, these are very close.

Regarding the comparison between the GAS $(2,2)$ models with gamma distribution and GAS $(2,2)$ with normal distribution, in the two tests, Wilcoxon and Diebold \& Mariano, the alternative hypothesis is not rejected, and the GAS model $(2,2)$ with gamma distribution, is more accurate than the GAS model $(2,2)$ with normal distribution.

According to Table 8 , in the comparison of GAS $(2,2)$ models with normal distribution and GAS $(2,2)$ models 
with beta distribution, in the Diebold \& Mariano test, is possible to accept the hypothesis that the GAS model $(2,2)$ with normal distribution and the GAS model $(2,2)$ with distribution generate predictions of the same accuracy. Note that the following hypothesis have been rejected: the model with normal distribution is more accurate than the model with beta distribution. As it can be seen in Table 6, the MAPE of the model with normal distribution is more than double the MAPE of the model with beta distribution, so this hypothesis would not be the most appropriate. Regarding Wilcoxon's non-parametric test, it accepts the hypothesis that the adjustment provided by the model with normal distribution is better than the adjustment provided by the beta distribution model. As the Wilcoxon test is a test of counts of a dichotomous variable, the result shows that in a higher number of times the errors of the beta distribution model were higher than the errors presented by the model with normal distribution.

The Figure 2 presents the time series formed by the Yield Curve levels from January 2006 to February 2017, the predictions within the sample (06/12 to $02 / 17)$ and the predictions out of the sample $(03 / 17$ to $02 / 19)$.

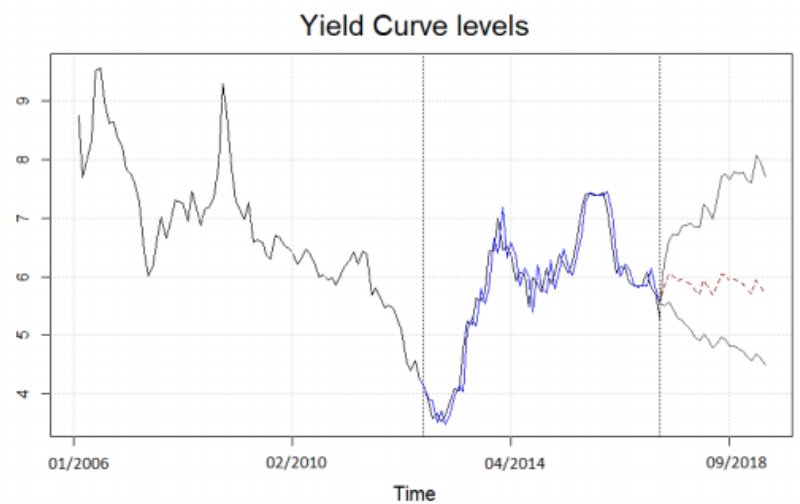

Figure 2. The Yield Curve levels from January 2006 to February 2017 and forecasts within and outside the sample

The predictions within the sample (from September 2012 to February 2017) were used to calculate the accuracy measurements shown in Table 7 and are shown in blue in Chart 2. As above mentioned, the GAS model $(2,2)$ with gamma distribution can be considered as a model with good adherence to real data.

As in most non-linear and non-Gaussian models, GAS models do not have analytic expressions for the computation of $y_{t+k \mid t}$ when $k>1$ (See Equation 2). The forward k-step predictions were obtained by Monte Carlo (Note 6) simulation.

The Figure 2 presents the prediction of the Yield Curve levels from March 2017 until February 2019 in red. According to the selected model - GAS model $(2,2)$ with gamma distribution - the long-term interest rates of the Brazilian economy may present a certain stability in the selected period for the out-of-sample prediction. The Table 9 presents some recent forecasts and actual data. For these predictions the following error measures were found: MAPE (\%): 8.53; EQM; 4.11 $\left(+10^{-5}\right)$ and Pseudo $R^{2}: 32.0 \%$.

Table 9. Forecasts (GAS $(2,2)$ with gamma distribution) and the Yield Curve levels

\begin{tabular}{|c|c|c|c|c|c|}
\hline Date & Forecasts & Rates & Date & forecasts & Rates \\
\hline sep-17 & 7.4 & 8.2 & jun-18 & 6.2 & 6.4 \\
\hline oct-17 & 7.4 & 8.2 & jul-18 & 5.9 & 6.4 \\
\hline nov-17 & 7.4 & 7.4 & aug-18 & 5.8 & 6.4 \\
\hline dec-17 & 7.4 & 6.4 & sep-18 & 5.8 & 6.4 \\
\hline jan-18 & 7.4 & 6.4 & oct-18 & 5.8 & 6.4 \\
\hline feb-18 & 7.2 & 6.4 & nov-18 & 6.1 & 6.4 \\
\hline mar-18 & 6.5 & 6.4 & dec-18 & 5.8 & 6.4 \\
\hline apr-18 & 6.1 & 6.4 & jan-19 & 5.7 & 6.4 \\
\hline may-18 & 6.2 & 6.4 & feb-19 & 5.3 & 6.4 \\
\hline
\end{tabular}


The interest rate is a relevant monetary policy instrument, strongly related to expectations of inflation. Thus, when we observe a lower long-term interest rate 6.4\% in December 2018, compared to the 2015 interest rates, may indicate a more stabilized inflation expectation by the monetary authority (See Table 10)

Table 10. Accumulated IPCA 12 months (IBGE - Brazilian Institute of Geography and Statistics)

\begin{tabular}{cc}
\hline Date & Accumulated IPCA \\
\hline 2014 & 6.41 \\
2015 & 6.29 \\
2016 & 10.67 \\
2017 & 2.95 \\
2018 & 3.75 \\
\hline
\end{tabular}

The prediction of the Yield Curve level through a model that generates a good adjustment becomes relevant for economic studies, especially because this variable has a strong relation with a very important macroeconomic variable for developing economies, the inflation.

\section{Discussion}

The article proposes the estimation of the level of the Brazilian Yield Curve - long-term rate, $\beta_{1}$ - using a new class of models called GAS (Generalized Autoregressive Score). The proposed models have as differentials: the fact that likelihood is available in closed form, which is not the case for models in state space with non-Gaussian distributions, and that the complete structure of the predictive distribution is transported to the time-varying parameter updating mechanism, via score function.

Using models with time-varying parameters called GAS models, it is possible to estimate all the components (level, slope and curvature) of the Yield Curve. This paper focused on the estimation and prediction of the long-term interest rate, $\beta_{1}$. To give continuity to this work, in the future, the other components of the ETTJ ( $\beta_{2}$ and $\beta_{3}$ ) will be estimated and predicted via GAS models $(\mathrm{p}, \mathrm{q})$ and, using the main components model, the Yield Curve will be constructed.

For the decision of the GAS model that best fits the database, the AIC and BIC criteria were used. A residual analysis using Homoscedasticity test, autocorrelation and normality was also made. It was also observed the adherence of the models inside and outside the sample, using the evaluation criteria MAPE, EQM and Pseudo $R^{2}$. Finally, to assist in the decision-making regarding the most appropriate model, the Wilcoxon and Diebold \& Mariano tests were employed. The tests have the purpose of comparing the accuracy of the predictions obtained through two different models. After all results analysis, it was concluded that the best fit to the series of the Brazilian Yield Curve level can be done via GAS model $(2,2)$ with gamma distribution.

As seen in the literature inherent to the theme, there is evidence that macroeconomic variables are directly linked to the components of the Yield Curve, given this evidence, it is extremely important that the components of the Yield Curve are appropriately modeled and predicted. This article contributes in this sense, proposing a suitable model for the estimation and prediction of the level component of the Yield Curve.

In finance, the use GAS models to predict Yield Curve Components such as level can be very helpful to identificate trade opportunities fixed income, or price arbitrages accros developing markets. The goal of more accurately modeling the Yield Curve components is linked, besides future financial gains, to the use of these as auxiliary variables to predict end of cycles of recession and economic growth, since authors as Ang e Piazzesi (2001), Wu (2003), Braum (2010), Diebolde Rudebusch (2013)showed relationships between the components of the Yield Curve and macroeconomic variables.

\section{References}

Ang, A., \& Piazzesi, M. (2001). A. No-Arbitrage Vector Autoregression of Term Structure Dynamics with macroeconomic and Latent Variables. Working Paper. Columbia University. Journal of Monetary Economics. https://doi.org/10.3386/w8363

Bernz, B. M. (2014). Modelo Nelson-Siegel dinâmico da estrutura a termo da taxa de juros com fatores exógenos macroeconômicos: uma aplicação ao mercado brasileiro. Dissertação apresentada ao Programa de Mestrado Profissional em Economia da Fundação Getúlio Vargas EESP. Brazil.

Braum, L. F. (2013). Risco de Taxas de Juros em Fundo de Ações - o Impacto de Nível, Inclinação e Curva de 
Juros da Estrutura a Termo. Dissertação apresentada no departamento Intituto de Gestão de Riscos e Atuariais da Pontificia Universidade Catolica do Rio de Janeiro. Brazil.

Chirinos-Leañez, A. M., \& Pagliacci, C. (2015). Macroeconomic shocks and the forward yield curve: How important is monetary policy?. Macroeconomics and Finance in Emerging Market Economies, 8(3), 201-223. https://doi.org/10.1080/17520843.2015.1049640

Creal, D. D., Koopman, S. J., \& Lucas, A. (2008). A General Framework for Observation Driven Time-Varying Parameter Models. Tinbergen Institute Discussion Paper, (4), 08-108. http://doi.org/10.2139/ssrn.1297183

Diebold, F. X., \& Li, C. (2006). Forecasting The Term Structure Of Government Bond Yields. Journal of Econometrics, 130, 337-364. https://doi.org/10.3386/w10048

Diebold, F. X., \& Mariano, R. S. (1995). Comparing Predictive Accuracy. Journal of Business and Economic Statistics, 13, 253-265. https://doi.org/10.3386/t0169

Diebold, F. X., \& Rudebusch, G. D. (2013). Yield Curve Modeling and Forecasting: The Dynamic Nelson-Siegel Approach. Princeton University Press, N. 5. https://doi.org/10.1515/9781400845415

Durbin, J., \& Koopman, S. (2001). Time Series Analysis by Space State Methods. Oxford University Press.

Ejsing, J., Garcia, J. A., \& Werner, T. (2007). The term structure of euro area break-even inflation rates: The impact of seasonality. European Central Bank.

Engle, R. F. (2002). New Frontiers for ARCH Models. Journal of Applied Econometrics, 17, 425-446. https://doi.org/10.1002/jae.683

Engle, R. F., \& Bollerslev, T. (1986). Modelling the persistence of conditional variances. Econometric Reviews, 5(1), 1-50. https://doi.org/10.1080/07474938608800095

Engle, R. F., \& Russell, J. R (1998). Autoregressive conditional duration: a new model for irregularly spaced transaction data. Econometrica, 66(5), 1127-1162. https://doi.org/10.2307/2999632

Ferreira, S. P. C. (2013). Comparação do desempenho das empresas do ponto de vista da reestruturação empresarial. Dissertação de Mestrado apresentada à Escola Superior de Tecnologia e Gestão do Instituto Politécnico de Leiria. Brazil.

Franklin, Jr, S. L., Duartre, T. B., Neves, C. R., \& Melo, E. F. (2012). A estrutura a termo de taxas de juros no Brasil: Modelos, estimação e testes. Economia Aplicada, 16(2), 255-290. https://doi.org/10.1590/S1413-80502012000200003

Koopman, S. J., Lit, R., \& Lucas, A. (2015). Intraday Stock Price Dependence using Dynamic Discrete Copula Distributions. Tinbergen Institute Discussion Paper, TI 15-037/III/DSF90. https://doi.org/10.2139/ssrn.2580840

LITTERMAN, R. \& SCHEINKMAN, J. (1991). Common Factors Affecting Bond Returns. The Journal of Fixed Income, 54-61. https://doi.org/10.3905/jfi.1991.692347

Luna, F. E. A. S. (2006). Aplicação da metodologia de Componentes Principais na análise da estrutura a termo de taxa de juros brasileira e no cálculo de Valor em Risco. Dissertação apresentada ao Instituto de Pós Graduação e Pesquisa em Administração - COPPEAD, da Universidade Federal do Rio de Janeiro - UFRJ. Brazil.

Mascitelli, P. H. (2008). Análise de Componentes Principais Dinâmicos Aplicados à Estrutura a Termo da Taxa de Juros. Dissertação apresentada ao Instituto de Economia da Universidade Federal do Rio de Janeiro, Mestrado em Economia.

Matos, G. G. (2013). GAS Models Applied to Time Series of Streamflow and Wind. Dissertação apresentada no departamento de Engenharia Elétrica na Pontifícia Universidade Católica do Rio de Janeiro.

Mensagem Presidencial. (2018). Projeto de Lei Orçamentária\} disponível em? Retrieved from http://www2.camara.leg.br/orcamento-da-uniao/leis-orcamentarias/loa/2006/tramitacao/proposta-do-poderexecutivo/Mensagem/7-divida _pub.pdf $>2006$

Obara V. H. (2014). Relação entre as componentes principais da estrutura a termo da taxa de juros brasileira e as variáveis macroeconômicas. Dissertação apresentada à Escola de Economia de São Paulo da Fundação Getúlio Vargas, Mestrado em Economia e Finanças. Brazil.

Shousha, S. (2008). Evidências sobre o Conteúdo Informacional da Estrutura a Termo da Taxa de Juros no Brasil. In VI Encontro Brasileiro de Finanças. 
Siegel, C. N. (1987). Parsimonious Modeling of Yield Curves. Journal of Business, 60(4), 473-489. https://doi.org/10.1086/296409

Sousa, L. G. de. (2004). Ensaios de economia. Edição eletrônica.

Svensson, L. E. O. (1994). Estimating and Interpreting Forward Interest Rates: Sweden 1992-1994. Sveriges Riksbank Quarterly Review, 13-26. https://doi.org/10.3386/w4871

Vicente, J. V. M., \& Graminho, F. M. (2015). Decompondo a inflação implícita. Revista Brasileira de Economia, 69(2), 263-284. https://doi.org/10.5935/0034-7140.20150012

Wilcoxon, F. (1945). Individual comparisons by ranking methods. Biometrics Bulletin, 1(6), 80-83. https://doi.org/10.2307/3001968

Wu, T. (2003). What Makes the Yield Curve Move? Economic Letter. Federal Reserve Bank of San Francisco, n. 2003-15, June 6.

\section{Notes}

Note 1. This is an example.

Note 2. This is an example for note 2.

Note 1. According to [14], the NTN-B are post-fixed securities that have their nominal value updated monthly, since the base date, by the variation of the inflation IPCA. These bonds pay coupon interest semiannually and redeem the principal on the maturity date.

Note 2. Brazilian Association of Financial and Capital Market Entities.

Note 3. Continue to conduct repurchase auctions of short-term securities, aiming at risk reduction of refinancing long-term securities, to stimulate liquidity; besides the early redemption of the NTN-B coupons, to increase the liquidity of this bond in the market. It will be attempted to have auctions of exchanging of securities maturing in the short term by longer ones, to reduce the risk of refinancing, increase liquidity and help to lengthen the profile of public debt (Presidential Message, Budget Law, 2006, p. 116.).

Note 4. The applied model was presented on page 39 (Durbin \& Koopman, 2001).

Note 5. we include the random walk as an additional naive model in the out-of-sample forecasts comparison.

Note 6. For further information, refer to Matos (2013).

\section{Copyrights}

Copyright for this article is retained by the author(s), with first publication rights granted to the journal.

This is an open-access article distributed under the terms and conditions of the Creative Commons Attribution license (http://creativecommons.org/licenses/by/4.0/). 